\section{Glue ear and grommets}

SIR,-The glue ear is such a common problem that your leading article (4 November, $p$ 1247) is welcome. Although fluid in the middle ear must not be ignored, it is rather sweeping to state that surgery is generally required and should not be postponed if fluid has not resolved within four to six weeks. Provided that the hearing loss is not marked, that the changes in the drum are minimal, and that pain and episodes of otitis media are not occurring there is no haste for myringotomy or the insertion of grommets. Glue ears frequently settle spontaneously, with normal drums and hearing: this includes those in which fluid has been known to be present for over four to six weeks.

T R BULL

London W1

\section{Grommets and swimming}

SIR,-While I agree with Mr P E Roland (4 November, p 1301) that children frequently have little trouble when swimming with grommets in situ, they must be advised against such activity at least if not wearing a suitably fitting ear plug (in which case they should not dive). In the Royal Naval Hospital Haslar ENT unit the problem was investigated with a life-size soft plastic model of the pinna, external auditory meatus, tympanic membrane, and middle ear. Grommets (ventilation tubes) of various types, from the original Sheppard to the soft Silastic models, were introduced into the artificial tympanic membrane. In a controlled experiment solutions of saline soapy water (to reduce surface tension) and tap water were introduced into the artificial meatus at varying pressures simulating varying depth under water. It should be remembered that at a depth of $33 \mathrm{ft}(10 \mathrm{~m})$ under water the meatal pressure is twice that at the surface-that is, two atmospheres. When breath-holding under water nasopharyngeal pressure and, with a patent eustachian tube, the pressure in the middle ear cleft remain at one atmosphere.

We have found in these experiments that water passes very freely through the grommets into the middle ear cleft, even when the pressure in the external meatus is at that of the surface (one atmosphere). In such situations infection or the results of chemical irritation may easily affect the middle ear mucosa. Personal experience in the outpatient clinic has confirmed that the majority of cases of childhood otitis media occurring in the summer following grommet insertion are the direct result of swimming, a cause-and-effect relationship being historically impossible to refute.

P W HEAD

Royal Naval Hospital,

Haslar,

Gosport, Hants

\section{Interpreting clinical trials}

SIR,-There may be confusion arising from the juxtaposition of two points in your leading article on this subject (11 November, p 1318). Frieman et al, ${ }^{1}$ in their survey of 71 "negative" trials, make their major point that the investigators did not pay enough (or any) attention to the relationship between the number of patients investigated and the chance of reporting a clinically interesting result. This led to some of the trials studied having a very low probability of detecting quite large differences between treatment and control: that is, they were studies of low power or high type II error. It is also pointed out that if some of the investigators had entered more patients a positive result might have been forthcoming.

The point in the leading article that setting confidence limits around the estimate of a difference between two treatments gives more information than merely reporting "no difference at $5 \%$ " is well made. It does need to be pointed out that reporting confidence limits at the end of a study does not absolve investigators from examining the power of the statistical tests used at the start.

The key question, "Am I going to be able to recruit enough patients to detect a clinically interesting result ?" must be asked right at the start. For the lone investigator with only one clinic or practice from which to recruit patients the problem is that the answer is quite likely to be "No."

In a straightforward comparison between two groups with success or failure as the only criterion the number of patients required for anything other than a once in a decade breakthrough rises rapidly into the hundreds. It is at this stage that the model investigator should send for the statistician. But that is another point.

London W6

IAN Clarke 'Frieman, J A, et al, New England fournal of Medicine,
1978, 299, 690.

\section{Hospital laboratory computing}

SIR,-Your leading article on hospital laboratory computing (18 February, p 387) has just come to my attention. It seems to imply that I am one of those who have given most attention to data acquisition. On the contrary, I have always believed, as you do, that processing is in fact most important.

It is doubly unfortunate, therefore, that I must disagree with your views on concurrent processing, complex operating software, easy inquiry facilities, and other notable achievements of the computer manufacturers. I have pointed out elsewhere that the clinical laboratory is essentially a batch operation: we receive test requests in batches, collect and process specimens in batches, deliver reports in batches. To force this system into the conventional real-time operating mould interferes with efficiency in laboratory utilisation.

An efficient laboratory system starts with a laboratory-dedicated minicomputer operated in batch mode; maintains a complete patient census, verified by laboratory personnel for laboratory purposes; provides an individualised computer-printed laboratory request form at regular intervals to each nursing unit, with all essential patient data already imprinted, to eliminate any transcription of requests by clinical or clerical personnel; returns a printed acknowledgment of test orders and specimens received to the nursing unit; documents each stage in the laboratory processing; cumulates results in logical order and inserts them in the patient's record; and delivers an individual report to each physician on a schedule appropriate to his respon- sibilities, informing him of current results on his list of patients. This last item is the key service that can be supplied by a laboratory computer system. None of the commercial systems I have seen offer it.

Systems based on these principles have been operating in a few hospitals in the US at a cost one-third or less of the conventional system cost. Is there a hospital laboratory in Britain that is interested in trying it ?

SAMUEL RAYMOND

Department of Pathology,

Philadelphia

\section{Physiotherapy in obstetrics and gynaecology}

SIR,-In September 1978, the Obstetric Association of Chartered Physiotherapists changed its title and became the Association of Chartered Physiotherapists in Obstetrics and Gynaecology, thus enlarging its work to include gynaecology in its range of activities. Many members of this specialist group within the Chartered Society of Physiotherapy have been working in this field for several years, giving pre-and post-operative treatments in physiotherapy, caring for all types of patients with varying conditions, among them the elderly and the incontinent. It has been felt for some time that more can be done to help patients with genital prolapse and pelvic laxity problems by giving effective muscular re-education to relieve symptoms, delaying surgery and perhaps preventing it from becoming necessary.

The role of such specialists is continuing to grow. They have much to offer towards improving the quality of life of women from pregnancy throughout the rest of their lives. There are now 400 of these physiotherapists working in Britain, in private practice and within the NHS, many of whom would be only too pleased to contribute towards improved patient health care and a reduction in hospital waiting lists.

Any medical practitioner wishing for further information should contact me or the secretary of the association, Mrs M Ellis, MCSP, 12 Bainbridge Holme Close, Sunderland, Tyne and Wear, who will be pleased to provide more details.

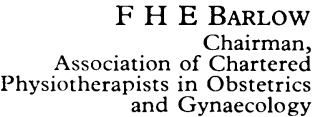

Greystones,

Chester-le-Street, Co Durham

\section{Intrauterine hiccup}

SIR,-I would like to comment on a phenomenon which has recently caused anxiety to several pregnant mothers.

Each mother complained of regular jerking movements made by her fetus during the last 6-8 weeks of pregnancy. The movements consisted of regular chronic jerks occurring at a frequency of one per second and lasting from three to six minutes. The activity occurred at any time but was most frequently noted in the evening or at night. In each case no abnormality was found in the baby after delivery, nor was there any suggestion of convulsive activity. In the most recent case the mother, who was medically qualified, was 